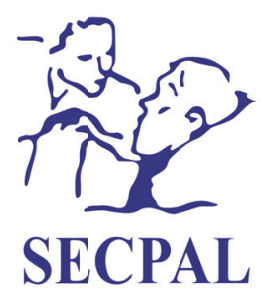

\title{
Compensación química y adicción a opioides: a propósito de los excedentes domiciliarios de opiáceos en cuidados paliativos
}

\author{
lago Villamil Cajoto*, Alicia Álvarez Pérez, Lucía Balea Vázquez y Carmen Martínez Lamas
}

Unidad de Hospitalización a Domicilio, Cuidados Paliativos, Hospital da Costa, Burela, Lugo, España

Recibido el 9 de noviembre de 2018

Aceptado el 21 de junio de 2019

Villamil Cajoto I, Álvarez Pérez A, Balea Vázquez L, Martínez Lamas C. Compensación química y adicción a opioides: a propósito de los excedentes domiciliarios de opiáceos en cuidados paliativos. Med Paliat. 2019;26(3):261-262.

\section{Sr. Director:}

Hemos leído con interés el trabajo de Gómez-del Valle y cols. ${ }^{1}$ de su revista. Coincidimos con los autores en que, tras implementarse los cuidados paliativos (CP), debe también implementarse el control de la exposición a opioides para disminuir el riesgo de su mal uso.

En las últimas décadas se ha observado en EE. UU. un importante aumento en la prescripción de opioides, que se ha asociado con un mal uso de los mismos, dando lugar a un aumento de muertes por sobredosis tras su uso no sanitario ${ }^{2,3}$. Esta epidemia tiene también una clara consecuencia económica, con pérdidas generadas estimadas de unos 504.000 millones de dólares en EE. UU. en 2105 (cerca de 430.000 millones de euros).

La formación del médico prescriptor sería el enfoque más acertado para controlar el mal uso de los opioides; esto permitiría individualizar la atención sobre las necesidades del paciente tras una evaluación beneficio-riesgo, limitando la compensación química o las adicciones ${ }^{1,2}$, pero esto no es suficiente. No está claro, por ejemplo, qué hacer con los medicamentos sobrantes, también los estupefacientes, que quedan en los domicilios.

La legislación actual dificulta el uso de los excedentes de fármacos y complica la gestión por la farmacia hospitala- ria. En nuestra comunidad autónoma existe la prohibición expresa de la recogida y reutilización de fármacos dispensados en oficina de farmacia extrahospitalaria. Existe alguna información sobre el manejo de excedentes de fármacos de uso hospitalario ${ }^{4}$, pero ninguna en cuanto a la recogida de estos excedentes en domicilio.

En nuestra unidad percibimos un excedente no cuantificado de fármacos en pacientes seguidos en CP, preocupándonos especialmente los estupefacientes. Durante el último año realizamos la recogida, clasificación y anotación del PVP de los estupefacientes retirados de los domicilios de los pacientes cuando finalizan los cuidados. Se atendieron entre agosto de 2017 y agosto de 2018 a 175 pacientes en CP. Se recuperaron en total 376 dosis de estupefacientes (incluidos morfina oral de liberación rápida y retardada, fentanilo transdérmico, transmucoso e intranasal, oxicodona y tapentadol) con PVP calculado de 4780 euros.

Consideramos muy relevante la cantidad de estupefacientes recuperada (en una unidad relativamente pequeña). Esto nos hace reflexionar que, por un lado, es posible que la prescripción sea excesiva y, por otro, si no lo es, como en general recomienda la literatura ${ }^{5,6}$, qué hacer con la custodia y posible utilización de excedentes. No disponemos de datos oficiales que valoren el volumen de estos, aunque en todas

\footnotetext{
*Autor para correspondencia:

lago Villamil Cajoto

Unidad Hospitalización a Domicilio, Cuidados paliativos, Hospital da Costa. c/ Rafael Vior, s/n, 27880, Burela, Lugo, España

Correo electrónico: Iago.Villamil.Cajoto@sergas.es
}

1134-248X/@ 2019 Sociedad Española de Cuidados Paliativos. Publicado por Inspira Network. Todos los derechos reservados. 
las conversaciones informales con otras unidades se coincide en la existencia de esta situación nunca cuantificada. La posibilidad de custodia y manejo de excedentes nos plantea que podría ser necesaria su regulación para no perder su control, ahora que la ola de abuso de opiáceos está en ciernes y por el propio mal uso de algunos casos, especialmente en procesos crónicos como los pacientes oncológicos de larga supervivencia descrito previamente ${ }^{1,5}$. Pero además, si este argumento no fuera más que un futurible, el elevadísimo precio de un material, que en otro caso sería directamente eliminado, debería hacernos pensar si esta falsa opulencia es impostada y, sobre todo, económicamente sostenible. Creemos que todo ello, al igual que las reflexiones del trabajo de Gómez del Valle y cols., son importantes para abordar un problema latente de dimensiones desconocidas y con implicaciones socioeconómicas y de salud pública relevantes en nuestra opinión.

\section{Conflicto de intereses}

No existe conflicto de intereses.

\section{Financiación}

El presente trabajo no ha recibido financiación de ningún tipo.

\section{Bibliografía}

1. Gómez del Valle MC, Zertuche-Maldonado T, Bruera E. Compensación química y adicción a opioides: evidencia, valoración de riesgo y manejo en pacientes con cuidados paliativos. Med $\mathrm{Pa}$ liat. 2018;25:281-90.

2. Alford DP. Opioid Prescribing for Chronic Pain. Achieving the Right Balance through Education. N Engl J Med. 2016;374:301-3.

3. Opioid Pain Medicines: Drug Safety Communication - New Safety Warnings Added to Prescription Opioid Medications. Consultado el 8 de julio de 2018. Disponible en: https: / /www.whitehouse.gov/sites/whitehouse.gov/files/images/The $\% 20$ Underestimated\%20Cost\%20of\%20the\%200pioid\%20Crisis.pdf.

4. Núñez Olarte JM, Francisco López MC, Conti Jiménez M, Sánchez Isac M, Pérez Aznar C, Solano Garzón ML, et al. Manejo de conductas aberrantes inducidas por opioides en una consulta externa de «cuidados paliativos precoces». Med Paliat. 2018;25:175-83.

5. Yuste-Vilaa D, Albert-Maria A, Jiménez-Arenas V, Jiménez-Torresa NV. Gestión de la devolución de tratamientos antineoplásicos y de su reutilización en pacientes oncológicos. Farm Hosp. 2009;33:217-22.

6. Berterame S, Erthal J, Thomas J, Fellner S, Vosse B, Clare P, et al. Use of and barriers to access to opioid analgesics: A worldwide, regional, and national study. Lancet. 2016;387:1644-56. 